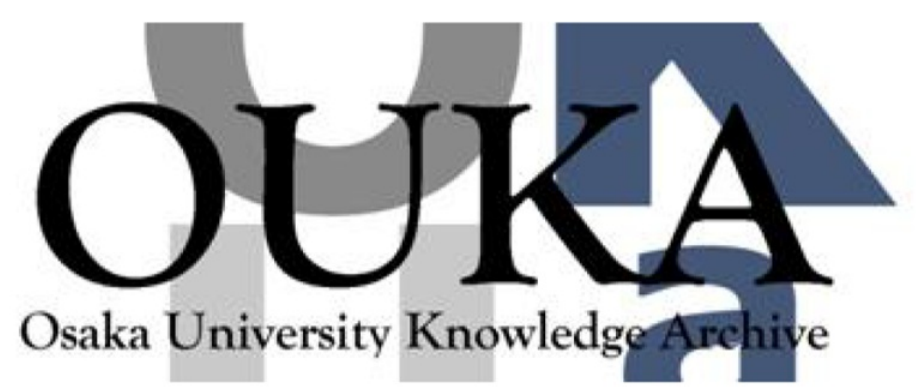

\begin{tabular}{|c|c|}
\hline Title & $\begin{array}{l}\text { CMOS voltage reference based on gate work } \\
\text { function differences in poly-Si controlled by } \\
\text { conductivity type and impurity concentration }\end{array}$ \\
\hline Author (s) & $\begin{array}{l}\text { Watanabe, Hirobumi; Ando, Shunsuke; Aota, } \\
\text { Hideyuki et al. }\end{array}$ \\
\hline Citation & $\begin{array}{l}\text { IEEE Journal of Solid-State Circuits. } 38(6) \\
\text { p. } 987-\text { p. } 994\end{array}$ \\
\hline Issue Date & $2003-06$ \\
\hline oaire:version & VoR \\
\hline URL & https://hdl. handle. net/11094/2899 \\
\hline rights & $\begin{array}{l}\text { ๑2003 IEEE. Personal use of this material is } \\
\text { permitted. However, permission to } \\
\text { reprint/republish this material for advertising } \\
\text { or promotional purposes or for creating new } \\
\text { collective works for resale or redistribution } \\
\text { to servers or lists, or to reuse any } \\
\text { copyrighted component of this work in other } \\
\text { works must be obtained from the IEEE.. }\end{array}$ \\
\hline Note & \\
\hline
\end{tabular}

Osaka University Knowledge Archive : OUKA

https://ir. Library. osaka-u. ac. jp/

0saka University 


\title{
CMOS Voltage Reference Based on Gate Work Function Differences in Poly-Si Controlled by Conductivity Type and Impurity Concentration
}

\author{
Hirobumi Watanabe, Member, IEEE, Shunsuke Ando, Hideyuki Aota, Masanori Dainin, Yong-Jin Chun, and \\ Kenji Taniguchi, Fellow, IEEE
}

\begin{abstract}
A new CMOS voltage reference circuit consisting of two pairs of transistors is presented. One pair exhibits a threshold voltage difference with a negative temperature coefficient $\left(-0.49 \mathrm{mV} /{ }^{\circ} \mathrm{C}\right)$, while the other exhibits a positive temperature coefficient $\left(+0.17 \mathrm{mV} /{ }^{\circ} \mathrm{C}\right)$. The circuit was robust to process variations and exhibited excellent temperature independence and stable output voltage. Aside from conductivity type and impurity concentrations of gate electrodes, transistors in the pairs were identical, meaning that the system was robust with respect to process fluctuations. Measurements of the voltage reference circuit without trimming adjustments revealed that it had excellent output voltage reproducibility of within $\pm 2 \%$, low temperature coefficient of less than $80 \mathrm{ppm} /{ }^{\circ} \mathrm{C}$, and low current consumption of $0.6 \mu \mathrm{A}$.
\end{abstract}

Index Terms-Low voltage, poly $\mathrm{Si}$, voltage reference, work function differences.

\section{INTRODUCTION}

$\mathbf{T}$ RADITIONAL voltage reference circuits can be classified into five different categories: bandgap reference circuits, which are based on bipolar integrated circuits and can be applied to CMOS circuits [1]-[4]; circuits based on threshold voltage $\left(V_{\mathrm{th}}\right)$ differences in MOS transistors [5]-[10]; MOS transistor circuits in which threshold voltage and mobility temperature dependencies are compensated for [11], [12]; current mode [13]; and beta multiplier (MOS based) [14]-[16]. Recent state of the art system LSIs, however, demand the use of voltage references which operate at low voltages, are robust to process fluctuations, exhibit low electrical current consumption, can be integrated with standard CMOS technologies, and allow flexible voltage adjustment [17]-[21]. Although bandgap reference circuits are extremely accurate, electrical current consumption is generally larger than MOS-based voltage references. MOStransistor-based voltage references, however, are susceptible to process fluctuations. Recently, low-power bandgap references have been studied [19].

A voltage reference is proposed that uses pairs of MOS transistors with positive and negative temperature coefficients.

Manuscript received April 12, 2002; revised December 11, 2002.

H. Watanabe, H. Aota, M. Dainin, and Y.-J. Chun are with the Electronic Devices Company, Ricoh Company Ltd., Osaka 563-8501, Japan (e-mail: hwata@nts.ricoh.co.jp).

S. Ando is with Torex Device Company, Ltd., Tokyo 103-0025, Japan.

$\mathrm{K}$. Taniguchi is with the Department of Electronics and Information Systems, Faculty of Engineering, Osaka University, Osaka 565-0871, Japan (e-mail taniguti@eie.eng.osaka-u.ac.jp).

Digital Object Identifier 10.1109/JSSC.2003.811974
The circuit is robust to process fluctuations because the reference voltage is derived from the difference in the work functions of the transistors, which are functions of gate electrode conductivity type and impurity concentration. Combination of positive and negative temperature coefficient components is a method for controlling temperature characteristics. Previous MOS transistor voltage references based on threshold voltage differences also utilized differences in the gate work functions of transistor pairs [7], [8], but without complementary temperature coefficients, accurate voltage references are not easily constructed [8]. Other attempts have used metal gates, which are not suitable to conventional CMOS processes [7]. A new CMOS voltage reference consisting of two pairs of transistors is presented. Theory, circuit implementations, and experimental results are also presented.

\section{THEORY OF WORK FunCTION DIFFERENCE}

Threshold voltage $V_{\text {th }}$ of MOS transistors (MOSFETs) is described as

$$
V_{\mathrm{th}}=V_{\mathrm{fb}}+\frac{q N_{a} W_{m}}{C_{\mathrm{ox}}}+\phi_{s}
$$

where

$V_{\mathrm{fb}}=\phi_{m s}-\frac{Q}{C_{\mathrm{ox}}}=\left(\psi_{m}-\psi_{s}\right)-\frac{Q}{C_{\mathrm{ox}}}, \quad W_{m}=\sqrt{\frac{2 \varepsilon_{\mathrm{si}} \cdot \phi_{s}}{q N_{a}}}$.

$V_{\mathrm{fb}}$ is flat-band voltage, $N_{a}$ is bulk dopant density, $W_{m}$ is depletion layer thickness, $C_{\mathrm{ox}}$ is gate-oxide capacitance per unit area, $\psi_{m}$ is the metal work function, $\psi_{s}$ is surface potential, $Q$ is the gate-oxide charge per unit area, $q$ is the magnitude of electronic charge, and $\varepsilon_{S i}$ is the dielectric constant of $\mathrm{Si}$ and $\phi s=2 \phi_{b}$ under conditions of strong inversion. Then $V_{\mathrm{th}}$ can be expressed as

$$
V_{\mathrm{th}}=\psi_{m}-\psi_{s}-\frac{Q}{C_{\mathrm{ox}}}+\frac{2 \sqrt{\varepsilon_{\mathrm{si}} \cdot q \cdot N_{a} \cdot \phi_{b}}}{C_{\mathrm{ox}}}+2 \phi_{b}
$$

where

$$
\begin{aligned}
\psi_{m} & =\frac{1}{q}\left(\chi_{\text {polySi }}+\frac{E g_{\text {polySi }}}{2}\right)+\phi_{\text {gate }} \\
\psi_{s} & =\frac{1}{q}\left(\chi_{\mathrm{Si}}+\frac{E g_{\mathrm{Si}}}{2}\right)+\phi_{b} .
\end{aligned}
$$

$\chi_{\text {poly-Si }}$ and $\chi_{\mathrm{Si}}$ are electron affinities of poly-Si and $\mathrm{Si}$, $E g_{\text {poly-Si }}$ and $E g_{\mathrm{Si}}$ are bandgaps of poly-Si and $\mathrm{Si}$, respectively. $\phi_{\text {gate }}$ is the potential difference between the Fermi 


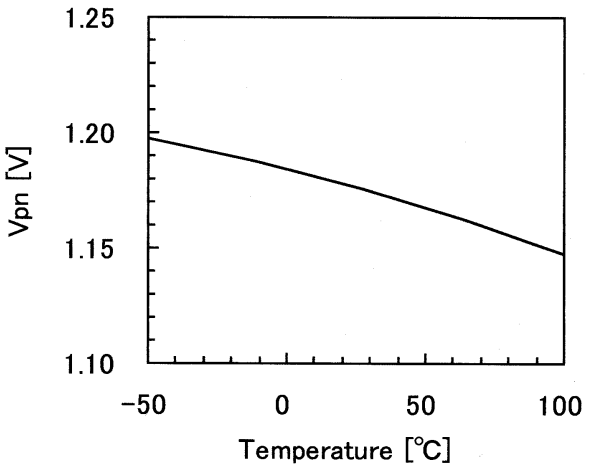

(a)

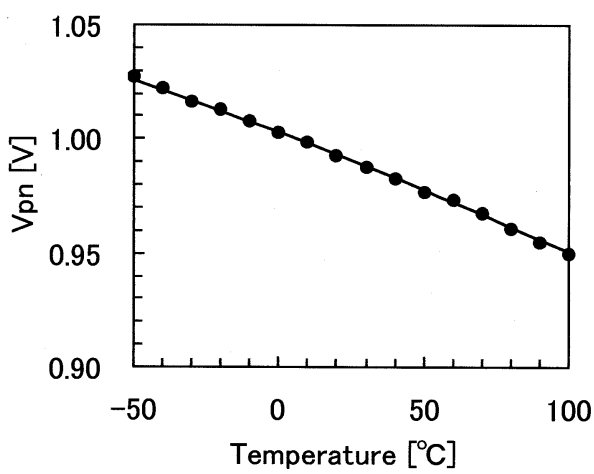

(b)

Fig. 1. $\quad V_{\text {pn }}$ as a function of temperature. (a) Simulation results based on Seto's model. (b) Experimental results.

level $E_{f}$ of poly-Si gates and intrinsic Fermi level $E_{i}$, and $\phi_{b}$ is the potential difference between the Fermi level $E_{f}$ of $\mathrm{Si}$ and intrinsic Fermi level $E_{i}$. In this paper, the poly-Si gate work function $\psi_{m}$ is regarded as a function of gate potential difference $\phi_{\text {gate }}$.

For a pair of MOS transistors with gates of different conductivity types or different impurity concentrations, all of the terms on the right-hand side (RHS) of (2) are equal except for $\psi_{m}$ terms, because substrate conditions are the same for both transistors. Thus, the difference in $V_{\mathrm{th}}\left(\Delta V_{\mathrm{th}}\right)$ between two transistors M1 and M2 is given by the difference in gate work function, as shown in (3). This contrasts with previously constructed MOS-based voltage references [5], [6], [8]-[10]

$$
\begin{aligned}
\Delta V_{\mathrm{th}}= & V_{\mathrm{th}_{\mathrm{M} 1}}-V_{\mathrm{th}_{\mathrm{M} 2}}=\psi_{m \mathrm{M} 1}-\psi_{m \mathrm{M} 2} \\
= & {\left[\frac{1}{q}\left(\chi_{\text {polySi }}+\frac{E g_{\mathrm{polySi}}}{2}\right)+\phi \text { gate }_{\mathrm{M} 1}\right] } \\
& -\left[\frac{1}{q}\left(\chi_{\text {polySi }}+\frac{E g_{\text {polySi }}}{2}\right)+\phi \text { gate }_{\mathrm{M} 2}\right] \\
= & \phi_{\text {gateM1 }}-\phi_{\text {gateM2 }}
\end{aligned}
$$

where

$$
\phi \text { gate }_{n}=-\frac{\left(E_{f n}-E_{i}\right)}{q}=-\frac{k T}{q} \cdot \ln \frac{N_{n}}{N_{i}}
$$

for n-type gates and

$$
\text { gate }_{p}=-\frac{\left(E_{i}-E_{f p}\right)}{q}=\frac{k T}{q} \cdot \ln \frac{N_{p}}{N_{i}}
$$

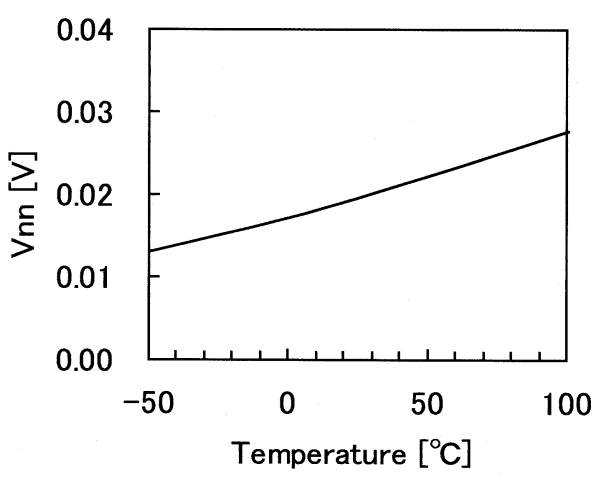

(a)

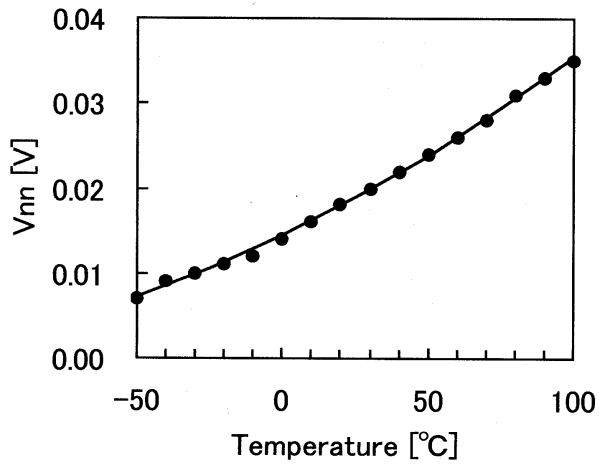

(b)

Fig. 2. $V_{\mathrm{nn}}$ as a function of temperature. (a) Simulation results based on Seto's model. (b) Experimental results.

for p-type gates. $N_{\mathrm{n}}$ and $N_{\mathrm{p}}$ are free carrier concentrations of n-type and p-type doped gates, respectively.

In the derivations of (4) and (5), gates with impurity concentrations less than degenerations levels were assumed crystalline silicon so that the Fermi-Dirac distribution could be applied.

For a pair of transistors with gates of opposite conductivity types, having impurity concentrations of $\mathrm{p}^{+}\left(\mathrm{B}^{+}: 4 \times 10^{19}\right.$ $\left.\mathrm{cm}^{-3}\right)$ and $\mathrm{n}^{+}\left(\mathrm{P}^{+}: 5 \times 10^{20} \mathrm{~cm}^{-3}\right)$, the $V_{\text {th }}$ difference $V_{\mathrm{pn}}$ between the $\mathrm{p}^{+}$and $\mathrm{n}^{+}$gate transistors is given by

$$
\begin{aligned}
V_{\mathrm{pn}} & =\phi \text { gate }_{\mathrm{p}^{+}}-\phi \text { gate }_{N^{+}} \\
& =\frac{k T}{q} \cdot \ln \frac{N_{\mathrm{p}+}}{N_{i}}-\left(-\frac{k T}{q} \cdot \ln \frac{N_{\mathrm{n}+}}{N_{i}}\right) \\
& =\frac{k T}{q} \cdot \ln \frac{N_{\mathrm{p}+} \cdot N_{\mathrm{n}+}}{N_{i}^{2}} .
\end{aligned}
$$

Simulation results using free carrier concentrations $N_{\mathrm{p}+}$ and $N_{\mathrm{n}+}$ derived from Seto's model [22] are shown in Fig. 1(a). Thus, $V_{\mathrm{pn}}$ exhibits a negative primary temperature coefficient together with a small negative secondary temperature coefficient due to the strong temperature dependence of $N_{i}$. Fig. 1(b) shows experimental measurements of $V_{\mathrm{pn}}$ as a function of temperature, which is well fitted by a quadratic regression equation given by

$$
V_{\mathrm{pn}}=-4.6 \times 10^{-7} \times T^{2}-4.9 \times 10^{-4} \times T+1.0 .
$$

Differences in $V_{\mathrm{pn}}$ between simulation and experiment may originate from both inaccurate estimations of active impurity concentrations and simplicity of the model used. 


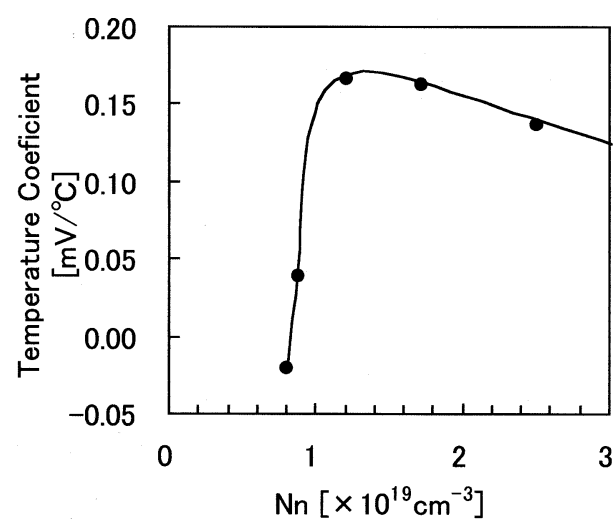

Fig. 3. $V_{\mathrm{nn}}$ primary temperature coefficient as a function of impurity concentration $N_{\mathrm{n}}$.

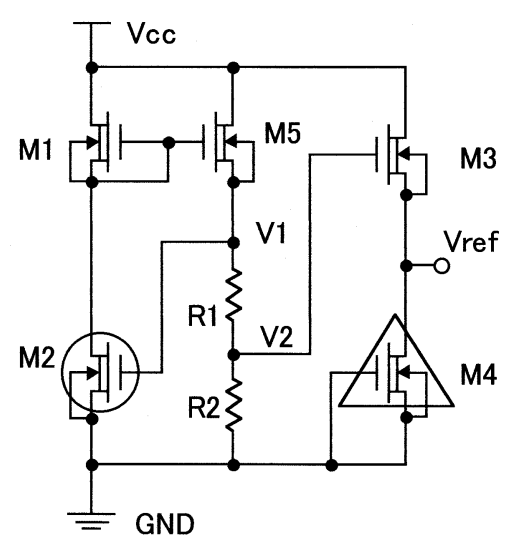

Fig. 4. Basic N-channel MOSFETs voltage reference. Circles indicate $\mathrm{p}^{+}$ gates, triangles indicate $n^{-}$gates, all others are $n^{+}$gate.

For a pair of transistors with gates of the same conductivity type, having gate impurity concentrations of $\mathrm{n}^{-}\left(\mathrm{P}^{+}: 1.7 \times\right.$ $\left.10^{19} \mathrm{~cm}^{-3}\right)$ and $\mathrm{n}^{+}\left(\mathrm{P}^{+}: 5 \times 10^{20} \mathrm{~cm}^{-3}\right)$, the $V_{\text {th }}$ difference $V_{\text {nn }}$ between the $\mathrm{n}^{-}$and $\mathrm{n}^{+}$gate transistors is given by

$$
\begin{aligned}
V_{\mathrm{nn}} & =\phi \text { gate }_{N^{-}}-\phi \text { gate }_{N^{+}} \\
& =-\frac{k T}{q} \cdot \ln \frac{N_{\mathrm{n}-}}{N_{i}}-\left(-\frac{k T}{q} \cdot \ln \frac{N_{\mathrm{n}+}}{N_{i}}\right) \\
& =\frac{k T}{q} \cdot \ln \frac{N_{\mathrm{n}+}}{N_{\mathrm{n}-}} .
\end{aligned}
$$

Both simulation and experimental determinations of the temperature dependence of $V_{\mathrm{nn}}$ show positive primary temperature coefficients and small positive secondary temperature coefficients, as shown in Fig. 2. The data is well fitted by a quadratic regression equation

$$
V_{\mathrm{nn}}=4.4 \times 10^{-7} \times T^{2}+1.7 \times 10^{-4} \times T+1.4 \times 10^{-2} .
$$

Primary temperature characteristics of $V_{\mathrm{nn}}$ depend on the impurity concentration of the $\mathrm{n}^{-}$gate. Fig. 3 shows measurements of temperature coefficient versus impurity concentration of the gate electrode. Note that temperature coefficient levels off around $1.4 \times 10^{19} \mathrm{~cm}^{-3}$, which is used to make the voltage reference robust with respect to process fluctuations.

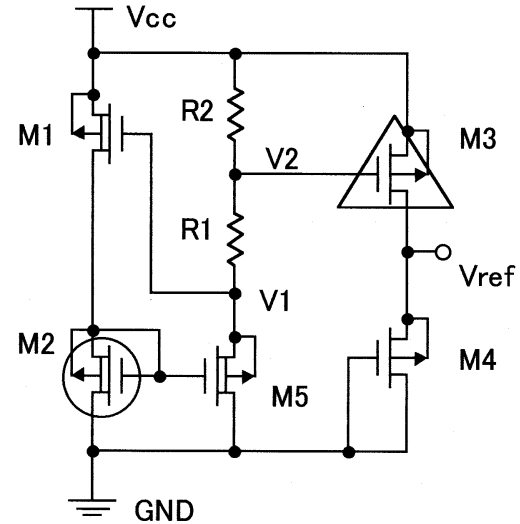

Fig. 5. P-channel MOSFETs voltage reference on a P-type substrate.

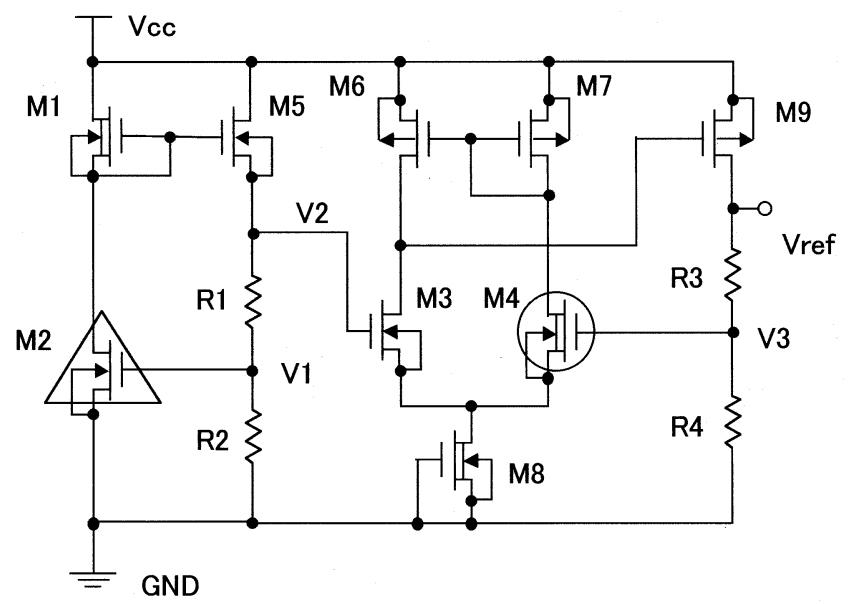

Fig. 6. Voltage reference with opamp.

\section{VOLTAGE REFERENCE}

From the primary temperature coefficients of $V_{\mathrm{pn}}=$ $-0.49 \mathrm{mV} /{ }^{\circ} \mathrm{C}$ and $V_{\mathrm{nn}}=0.17 \mathrm{mV} /{ }^{\circ} \mathrm{C}$ given in (7) and (9), it is evident that $V_{\mathrm{pn}}$ and $V_{\mathrm{nn}}$ could be combined in such a way that the primary temperature coefficient of a voltage reference $\left(V_{\text {ref }}\right)$ cancels out, giving

$$
V_{\text {ref }}=\frac{0.17}{0.49} \times V_{\mathrm{pn}}+V_{\mathrm{nn}}=2.8 \times 10^{-7} \times T^{2}+0.36
$$

The remaining secondary coefficient of $2.8 \times 10^{-7}$ is equivalent to $18 \mu \mathrm{V} /{ }^{\circ} \mathrm{C}$ over the temperature range of $-50^{\circ} \mathrm{C}-100^{\circ} \mathrm{C}$.

In this section, a circuit that utilizes the difference between work functions, that is, differences in $V_{\mathrm{th}}$, is described. For pairs of transistors, M1 and M2, driven by the same current and operating at saturation, the following equation holds:

$$
\begin{gathered}
I_{\mathrm{dsat} t_{\mathrm{M} 1}}-I_{\mathrm{dsat}_{\mathrm{M} 2}}=\frac{1}{2} C_{\mathrm{ox}_{\mathrm{M} 1}} \cdot \mu_{\mathrm{M} 1} \cdot \frac{W_{\mathrm{M} 1}}{L_{\mathrm{M} 1}}\left(V_{\mathrm{gs}_{\mathrm{M} 1}}-V_{\mathrm{th}_{\mathrm{M} 1}}\right)^{2} \\
-\frac{1}{2} C_{\mathrm{OX}_{\mathrm{M} 2}} \cdot \mu_{\mathrm{M} 2} \cdot \frac{W_{\mathrm{M} 2}}{L_{\mathrm{M} 2}}\left(V_{\mathrm{gs}_{\mathrm{M} 2}}-V_{\mathrm{th}_{\mathrm{M} 2}}\right)^{2}=0 .
\end{gathered}
$$

Matching the geometries of the transistors M1 and M2 gives

$$
C_{\mathrm{ox}_{1}}=C_{\mathrm{ox}_{2}}, \quad \mu_{1}=\mu_{2}, \quad \text { and } \quad \frac{W_{1}}{L_{1}}=\frac{W_{2}}{L_{2}}
$$




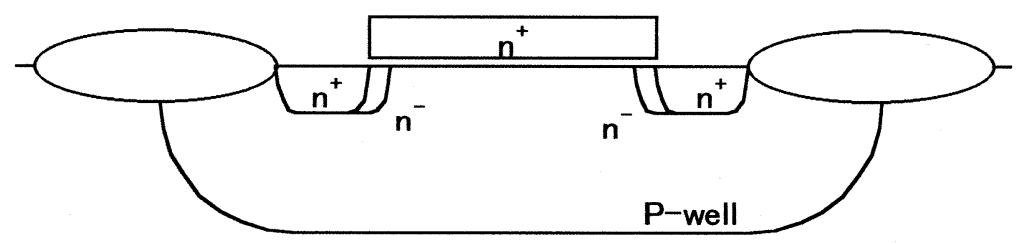

(a)

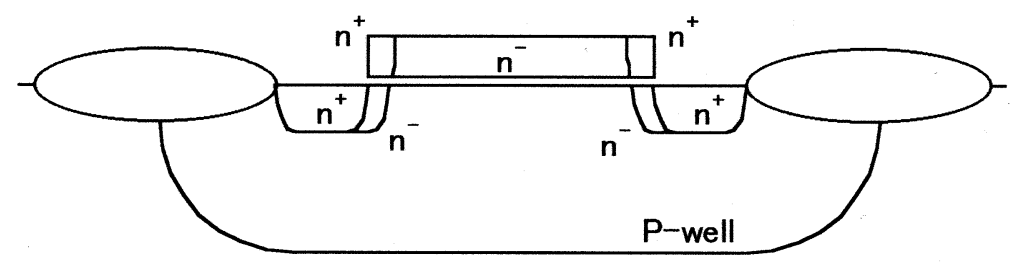

(b)

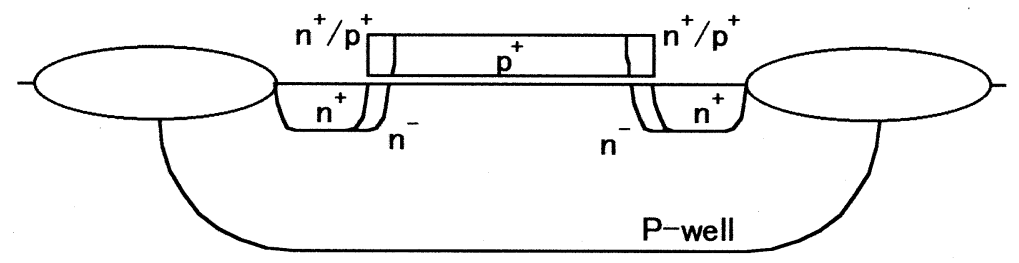

(c)

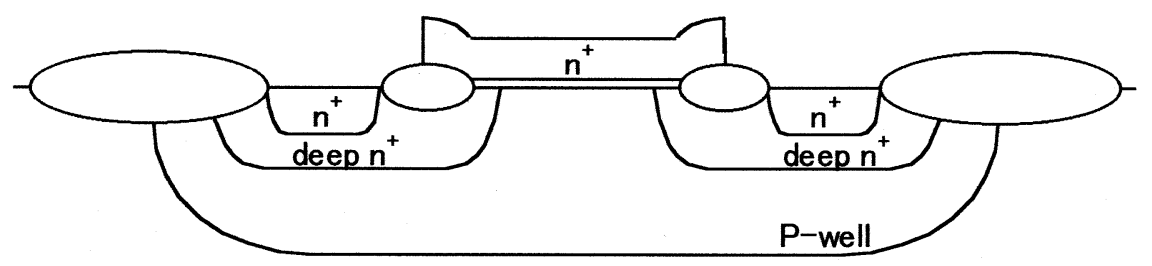

(d)

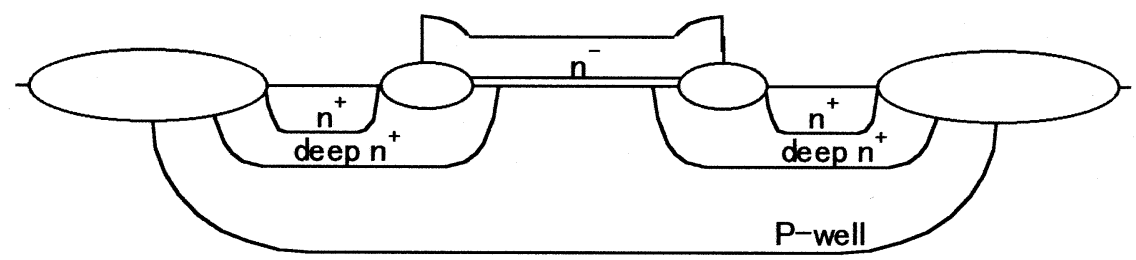

(e)

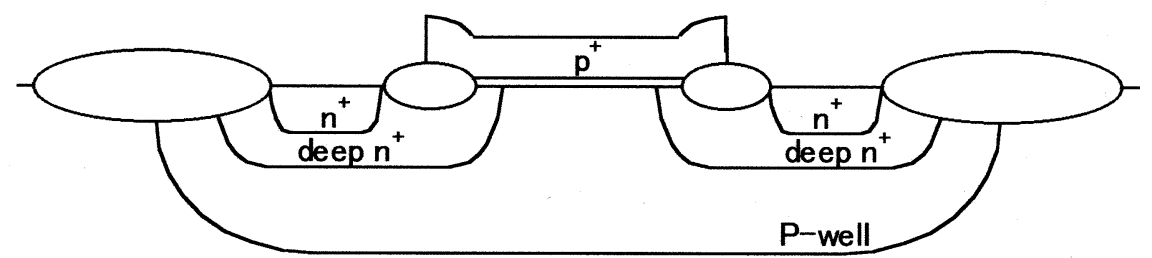

(f)

Fig. 7. Conventional and LOCOS offset N-channel MOSFETs. (a) Conventional $\mathrm{n}^{+}$gate. (b) Conventional $\mathrm{n}^{-}$gate. (c) Conventional $\mathrm{p}^{+}$gate. (d) LOCOS offset $\mathrm{n}^{+}$gate. (e) LOCOS offset $\mathrm{n}^{-}$gate. (f) LOCOS offset $\mathrm{p}^{+}$gate.

and so

$$
V_{\mathrm{th}_{\mathrm{M} 1}}-V_{\mathrm{th}_{\mathrm{M} 2}}=V_{\mathrm{gs}_{\mathrm{M} 1}}-V_{\mathrm{gs}_{\mathrm{M} 2}}
$$

The difference in $V_{\text {th }}$ between the two transistors can then be calculated from the difference in $V_{\mathrm{gs}}$.
To implement the theory in a circuit, two points need to be taken into consideration. First, (12) is valid only when the transistor pairs are placed in separate wells but have the same structure. Second, voltage reference has to be provided with respect to ground. Thus, a voltage reference circuit comprised of N-channel MOSFETs, as shown in Fig. 4, has advantages 
over circuits comprised of P-channel MOSFETs, as shown in Fig. 5, because N-channel MOSFETs in separate P-wells can directly produce $V_{\mathrm{gs}}$ relative to ground. This is not the case for P-channel MOSFETs without using triple wells, because P-channel MOSFETs can only generate the voltage reference with respect to $V_{c c}$, meaning that the output is offset from ground.

All transistors in the basic voltage reference circuit shown in Fig. 4 are N-channel MOSFETs in separate P-wells to which source electrodes are connected. The pair of transistors consisting of $\mathrm{n}^{+}$gate transistor $\mathrm{M} 1$ and $\mathrm{p}^{+}$gate transistor M2 are connected in series between the power supply and ground so that the difference between $V_{\mathrm{th}_{\mathrm{M} 1}}$ and $V_{\mathrm{th}_{\mathrm{M} 2}}$ is produced as $V_{\mathrm{gs}}$ of M2 $\left(=V_{1}=V_{\mathrm{pn}}\right)$. Transistor M1 is then a depletion mode transistor acting as a current source, while $V_{\mathrm{th}_{\mathrm{M} 1}}$ and $V_{\mathrm{th}_{\mathrm{M} 2}}$ are about -0.30 and $0.88 \mathrm{~V}$, respectively.

The other pair of transistors consists of $\mathrm{n}^{+}$gate transistor M3 and $\mathrm{n}^{-}$gate transistor M4. Note that $V_{\mathrm{gs}}$ of M3 $\left(=V_{2}-V_{\text {ref }}\right)$ is equal to the difference between $V_{\mathrm{th}_{\mathrm{M} 3}}$ and $V_{\mathrm{th}_{\mathrm{M} 4}}\left(=-V_{\mathrm{nn}}\right)$ because the gate electrode of M4 is connected to ground. Transistor M4 is then a depletion mode transistor acting as current source, and $V_{\mathrm{th}_{\mathrm{M} 3}}$ and $V_{\mathrm{th}_{\mathrm{M}} 4}$ are about -0.30 and $-0.35 \mathrm{~V}$, respectively.

Transistor M5, with $V_{\mathrm{th}_{\mathrm{M} 5}}$ of about $-0.30 \mathrm{~V}$, sits between the two pairs of transistors, and in combination with the resistors forms a source-follower circuit that works as a level shifter to define the drain voltage of $\mathrm{M} 2$. In addition, the voltage $V_{\mathrm{pn}}$ is divided using R1 and R2 and then input to the gate of M3. The final output voltage $V_{\text {ref }}$ is then given by

$$
V_{\mathrm{ref}}=\frac{R 2}{R 1+R 2} \times V_{\mathrm{pn}}+V_{\mathrm{nn}} .
$$

The ratio of $\mathrm{R} 1$ to $\mathrm{R} 2$ can then be adjusted to make the primary temperature coefficient zero. The sum of the resistances of R1 and R2 can be chosen depending on the current consumption target. Resistances of R1 and R2 were chosen to be 2976 and $2024 \Omega /$ sq., respectively, for all following experiments.

For the voltage reference circuit composed of P-channel transistors placed in separate N-wells, as shown in Fig. 5, the pair of transistors $\mathrm{M} 1$ and $\mathrm{M} 2$ generate $V_{\mathrm{pn}}$, which is equal to $V_{c c}-V_{1}$. The voltage $V_{2}$ generated by dividing $V_{\mathrm{pn}}$ using R1 and R2 is then input to the gate of $\mathrm{n}^{-}$gate transistor M3, similar to the circuit shown in Fig. 4. Note that $V_{\mathrm{gs}}$ of $\mathrm{n}^{+}$gate transistor M4 produces $V_{\text {ref }}$ relative to ground that is shifted $(R 2 /(R 1+R 2) \times$ $\left.V_{\mathrm{pn}}\right)$ relative to $V_{\mathrm{nn}}$.

Output reference voltage $V_{\text {ref }}$ is then given uniquely by $V_{\mathrm{pn}}$ and $V_{\mathrm{nn}}$ as shown in (13).

To generate an arbitrary reference voltage $V_{\text {ref }}$, an additional amplifier is required. Fig. 6 shows a circuit that utilizes the differential input from $\mathrm{n}^{+}$gate transistor $\mathrm{M} 3$ and $\mathrm{p}^{+}$gate transistor M4, which are simultaneously part of an operational amplifier (opamp) circuit. In the circuit, $V_{\mathrm{pn}}$ is derived from

$$
V_{\mathrm{pn}}=V_{3}-V_{2}
$$

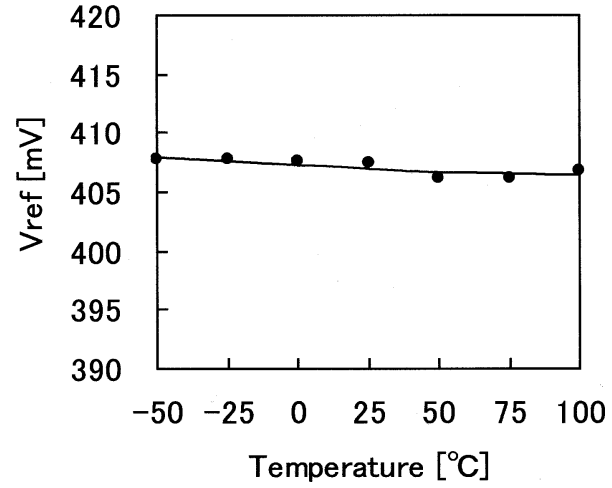

(a)

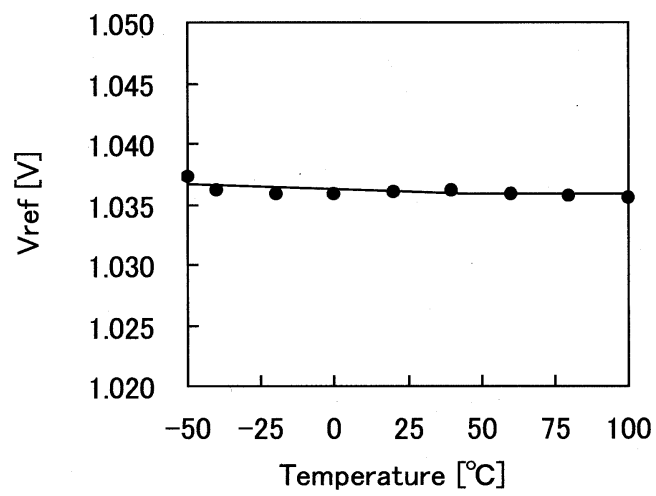

(b)

Fig. 8. $\quad V_{\text {ref }}$ as a function of temperature. (a) Circuit shown in Fig. 4. (b) Circuit shown in Fig. 6.

where

$$
V 2=\frac{R 1+R 2}{R 2} \times V_{\mathrm{nn}}
$$

Then

$$
V_{3}=\frac{R 1+R 2}{R 2} \times V_{\mathrm{nn}}+V_{\mathrm{pn}}
$$

Arbitrary reference voltage $V_{\text {ref }}$ is then given by

$$
V_{\text {ref }}=\left(1+\frac{R 3}{R 4}\right) \times V_{3}
$$

Furthermore, temperature characteristics of the circuit block driven by $V_{\text {ref }}$ can be also be compensated for by simply adjusting the ratios of $\mathrm{R} 1$ to $\mathrm{R} 2$ and $\mathrm{R} 3$ to $\mathrm{R} 4$.

\section{EXPERIMENTS AND RESULTS}

\section{A. Device Structure}

Voltage reference circuits were fabricated with conventional CMOS technology using a high-resistivity resistor process, producing separate $\mathrm{P}$-wells and $\mathrm{N}$-wells in the $\mathrm{N}$-substrate. MOSFET gate-oxide thickness is $30 \mathrm{~nm}$ and poly-Si gate thickness is $500 \mathrm{~nm}$. Gate electrodes of all of the transistors and resistors were composed of the same poly-Si, but were doped using different processes. Phosphorous doping was performed using PSG deposition to form $\mathrm{n}^{+}$(heavily doped) gates. $\mathrm{P}^{+}$ 
TABLE I

Vref Characteristics Versus Process VARIation

\begin{tabular}{c|c|c}
\hline $\begin{array}{c}\text { Process Parameter } \\
\text { Variation }\end{array}$ & $\begin{array}{c}\text { Deviation }(3 \sigma) \\
\text { of Vref at } 25^{\circ} \mathrm{C}\end{array}$ & $\begin{array}{c}\text { Temperature } \\
\text { Coefficient }\end{array}$ \\
\hline Tox $\pm 7 \%$ & $1.7 \%$ & $56 \mathrm{ppm} /{ }^{\circ} \mathrm{C}$ \\
\hline Vth $\pm 23 \%$ & $1.6 \%$ & $59 \mathrm{ppm} /{ }^{\circ} \mathrm{C}$ \\
\hline Poly Si Resistance $\pm 20 \%$ & $1.7 \%$ & $80 \mathrm{ppm} /{ }^{\circ} \mathrm{C}$ \\
\hline
\end{tabular}

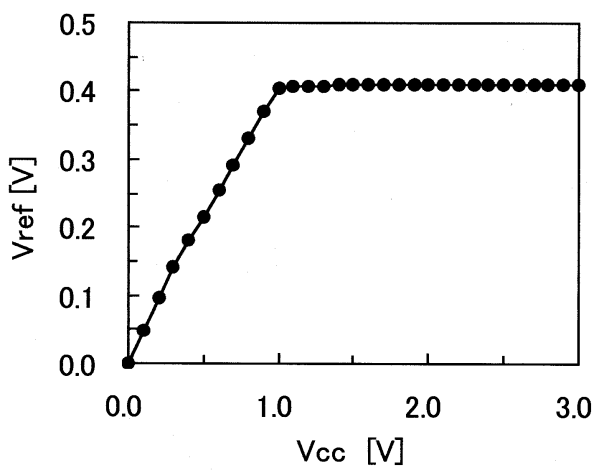

Fig. 9. $\quad V_{\text {ref }}$ as a function of supply voltage.

(heavily doped) gates, $\mathrm{n}^{-}$(lightly doped) gates, and resistances regions were covered by $\mathrm{SiO}_{2}$ film during the $\mathrm{n}^{+}$(heavily doped) gate-doping process. $\mathrm{P}^{+}$gates, $\mathrm{n}^{-}$gates, and resistors were doped by ion implantation with impurity concentrations of $\mathrm{B}^{+}: 4 \times 10^{19} \mathrm{~cm}^{-3}, \mathrm{P}^{+}: 1.7 \times 10^{19} \mathrm{~cm}^{-3}$, and $\mathrm{P}^{+}: 8.0 \times$ $10^{18} \mathrm{~cm}^{-3}$, respectively. The boron ion implantation process was used to simultaneously dope $\mathrm{P}^{+}$gates and $\mathrm{P}$-channel MOSFET source and drain. The phosphorous concentration of resistors differed from that of $\mathrm{n}^{-}$gates. If the phosphorous concentration of the resistors had been chosen to be the same as that of the $\mathrm{n}^{-}$gates, one step in the fabrication process could have been eliminated.

Both conventional and LOCOS offset transistors with separate source and drain from the active region were manufactured. In the case of conventional transistors, as shown in Fig. 7(a), phosphorous implantation for source/drain was carried out using the self-alignment method, leading to an increase in phosphorus concentration near the edge of the $\mathrm{n}^{-} / \mathrm{p}^{+}$gate. In order to avoid this, LOCOS offset structure transistors were fabricated, as shown in Fig. 7(b), in which ion implantation beneath the LOCOS was carried out to reduce parasitic resistance. This ion implantation represents an additional process that is not needed in fabrication of conventional transistors.

Differences in characteristics of the two structures were evaluated from the dispersion of $V_{\text {ref. }}$. There was no appreciable difference between the two structures for transistors with channel lengths of over $100 \mu \mathrm{m}$, but deviations in $V_{\mathrm{th}}$ for conventional transistors became larger than for LOCOS offset transistors for channel lengths of less than $50 \mu \mathrm{m}$. Deviation of conventional transistors was $3 \sigma=0.9 \%$ and that of LOCOS offset ones $3 \sigma=1 \%$ for transistors with $L=100 \mu \mathrm{m}$. This is due to the gate length being too large to have any influence on edge

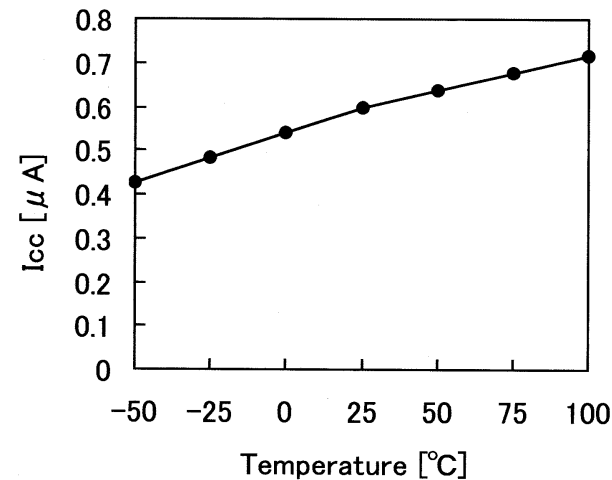

(a)

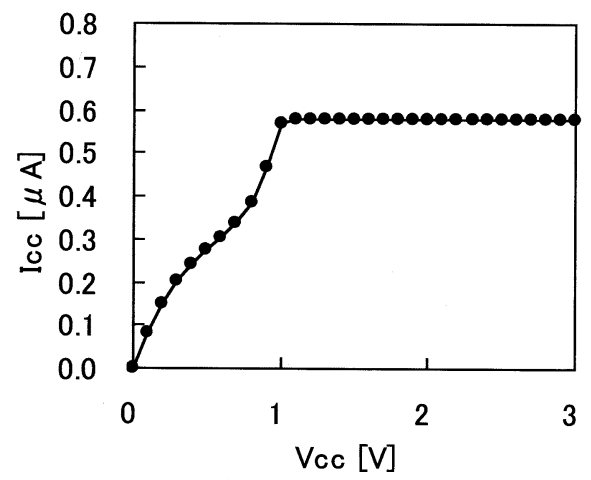

(b)

Fig. 10. $I_{c c}$ as a function of (a) temperature and (b) $V_{c c}$.

phenomena. Conventional transistors with dimensions $W / L=$ $10 \mu \mathrm{m} / 100 \mu \mathrm{m}$ were chosen for the rest of this work.

\section{B. Temperature Characteristics}

Fig. 8 shows the measured $V_{\text {ref }}$ of the voltage reference circuit as a function of temperature without trimming. A ratio of 0.405 for the series resistors R2/(R1 + R2) was used. A small negative temperature dependence that is not well expressed by quadratic regression equations remained, due to the small temperature dependence of R1/R2 ratio for temperatures below $25^{\circ} \mathrm{C}$. Temperature coefficient of the reference voltage measured using the box method was $50 \mathrm{ppm} /{ }^{\circ} \mathrm{C}$. The ratio $\mathrm{R} 2 /(\mathrm{R} 1+\mathrm{R} 2)$ may also be adjusted by trimming to achieve even more accurate voltage reference circuits.

\section{Robustness}

In principle, since the proposed voltage reference is based on $V_{\mathrm{pn}}$ and $V_{\mathrm{nn}}$, which are derived from differences in gate work function as given by (3), output voltage of the system should not fluctuate under process variations as long as both pairs of transistors are subject to the same process variations. Diffusion of impurities to the poly-Si gate electrodes is the only independently controlled process during fabrication. Because poly-Si impurity concentration $N_{\mathrm{n}}$ can be chosen so that temperature coefficient of $V_{\mathrm{nn}}$ is very stable with respect to changes in impurity concentrations, as shown in Fig. 3, the proposed voltage reference circuit is expected to be robust to process variations. Experimental results, as summarized in Table I, show that $3 \sigma$ 
TABLE II

Voltage Reference Performance Benchmark Indicators

\begin{tabular}{c|c|c|c|c|c}
\hline Type & $\mathrm{V}_{\text {ref }}$ & $3 \sigma$ & $\mathrm{I}_{\mathrm{cc}}$ & $\mathrm{V}_{\mathrm{cc}}$ & $\begin{array}{c}\text { Temperature } \\
\text { Coefficient }\end{array}$ \\
\hline Circuit in Fig. 4 & $0.41 \mathrm{~V}$ & $1.7 \%$ & $0.6 \mu \mathrm{A}$ & $>1$ & $<80 \mathrm{ppm} /{ }^{\circ} \mathrm{C}$ \\
\hline$[8]^{*}$ & $1.2 \mathrm{~V}$ & $5 \%(\mathrm{max} / \mathrm{min})$ & $<1 \mu \mathrm{A}$ & $>2$ & $\pm 30 \mathrm{ppm} /{ }^{\circ} \mathrm{C}$ \\
\hline$[10]^{*}$ & $0.30 \mathrm{~V}$ & $4 \%(\mathrm{max} / \mathrm{min})$ & $9.7 \mu \mathrm{A}$ & $>1.4$ & $<62 \mathrm{ppm} /{ }^{\circ} \mathrm{C}$ \\
\hline$[18]^{* *}$ & $0.51 \mathrm{~V}$ & $3 \%$ & $2 \mu \mathrm{A}$ & 2.1 & - \\
\hline$[19]^{* *}$ & $0.65 \mathrm{~V}$ & $6 \%$ & $<1.2 \mu \mathrm{A}$ & $>0.85$ & $57 \mathrm{ppm} /{ }^{\circ} \mathrm{C}$ \\
\hline
\end{tabular}

$*$ : MOS $\mathrm{V}_{\mathrm{th}}$ difference based, ** : Band-gap circuit

deviations of $V_{\text {ref }}$ for circuits fabricated under a wide range of process variations were kept within $\pm 2 \%$, while temperature coefficients of less than $80 \mathrm{ppm} /{ }^{\circ} \mathrm{C}$ were obtained without trimming the resistors.

\section{Operation Voltage and Electrical Current Consumption}

Fig. 9 shows $V_{\text {ref }}$ characteristics as a function of supply voltage, indicating that the minimum operating voltage is about 1 V. Minimum supply voltage of the circuit in Fig. 4 is given theoretically by

$$
V_{\min }=V_{\mathrm{pn}}+V_{\mathrm{th}_{\mathrm{M} 5}}-V_{\mathrm{th}_{\mathrm{M} 1}} .
$$

Electrical current consumption $I_{c c}$ is $0.6 \mu \mathrm{A}$ at $25^{\circ} \mathrm{C}$, with no exponential increase, even up to temperatures of $100^{\circ} \mathrm{C}$, as shown in Fig. 10(a). Even if thermal junction leakage current increases, $V_{\text {ref }}$ remains relatively constant because it originates from work function differences, which are relatively independent of leakage currents. $I_{c c}$ is also largely independent of $V_{c c}$, as shown in Fig. 10(b).

Table II shows a list of measured voltage reference performance benchmarks. Properties of the circuit presented in Fig. 4 are shown in the first row, with values from other works shown for comparison.

\section{CONCLUSION}

A CMOS voltage reference based on two pairs of transistors was presented. One pair of transistors consisted of $n^{+}$and $p^{+}$gate transistors, and had a negative temperature coefficient of threshold voltage difference $\left(-0.49 \mathrm{mV} /{ }^{\circ} \mathrm{C}\right)$. The other pair consisted of $n^{+}$and $n^{-}$gate transistors, and had a positive temperature coefficient $\left(+0.17 \mathrm{mV} /{ }^{\circ} \mathrm{C}\right)$. Measurements were conducted without trimming adjustments, and confirmed that the voltage reference had: 1) excellent output voltage reproducibility within $\pm 2 \%$; 2) low temperature coefficient of less than $80 \mathrm{ppm} /{ }^{\circ} \mathrm{C}$; and 3) a low current consumption of $0.6 \mu \mathrm{A}$.

\section{REFERENCES}

[1] A. P. Brokaw, "A simple three-terminal IC bandgap reference," IEEE J. Solid-State Circuits, vol. SC-9, pp. 388-393, Dec. 1974.

[2] E. Vittoz and O. Neyroud, "A low-voltage CMOS bandgap reference," IEEE J. Solid-State Circuits, vol. SC-14, pp. 573-577, Dec. 1979.
[3] M. Ferro, F. Salerno, and R. Castello, "A floating CMOS bandgap voltage reference for differential applications," IEEE J. Solid-State Circuits, vol. 24, pp. 690-697, June 1989.

[4] S. Gupta and W. Black, "A 3 to 5 V CMOS bandgap voltage reference with novel trimming," in IEEE 39th Midwest Symp. Circuits and Systems, vol. 2, 1996, pp. 969-972.

[5] R. A. Blauschild et al., "A new NMOS temperature-stable voltage reference," IEEE J. Solid-State Circuits, vol. SC-13, pp. 767-774, 1978.

[6] M. E. Hoff, "MOS voltage reference circuit," U.S. Patent 4100437 , 1978.

[7] M. C. Tobey et al., "Flatband voltage reference," U.S. Patent 3975648 , 1978.

[8] H. J. Oguey and B. Gerber, "MOS voltage reference based on poly silicon gate work function difference," IEEE J. Solid-State Circuits, vol. SC-15, pp. 264-269, Dec. 1980.

[9] H.-J. Song and C.-K. Kim, "A temperature-stabilized SOI voltage reference based on threshold voltage difference between enhancement and depletion NMOSFET's," IEEE J. Solid-State Circuits, vol. SC-28, pp. 671-677, June 1993.

[10] K. N. Leung and P. K. Mok, "A CMOS voltage reference based on weighted difference of gate-source voltages between PMOS and NMOS transistors for low dropout regulators," in 2001 Eur. Solid-State Circuit Conf., 2001

[11] T. Manku and Y. Wang, "Temperature-independent output voltage generated by threshold voltage of an NMOS transistor," Electron. Lett., vol. 31, no. 12, pp. 935-936, June 1995.

[12] I. M. Filanovsky and A. Allam, "Mutual compensation of mobility and threshold voltage temperature effects with applications in CMOS circuits," IEEE Trans. Circuits Syst., vol. 48, pp. 876-884, July 2001.

[13] R. Stair et al., "A current mode CMOS voltage reference," in Proc. Southwest Symp. Mixed-Signal Design, 2000, pp. 23-26.

[14] E. Vittoz and J. Fellrath, "CMOS analog integrated circuits based on weak inversion operation," IEEE J. Solid-State Circuits, vol. SC-12, pp. 224-231, June 1977.

[15] H.-J. Yoo et al., "A precision CMOS voltage reference with enhanced stability for the application to advanced VLSIs," in Proc. IEEE Int. Symp. Circuits and Systems, vol. 2, May 1993, pp. 1318-1321.

[16] L. Song and R. J. Baker, "Process and temperature performance of a CMOS beta-multiplier voltage reference," in Proc. Midwest Symp. Circuits and Systems, 1998, pp. 33-36.

[17] K.-M. Tham and K. Nagaraj, "A low supply voltage high PSRR voltage reference in CMOS process," IEEE J. Solid-State Circuits, vol. 30, pp. 586-590, May 1995.

[18] H. Banba et al., "A CMOS bandgap reference circuit with sub $1 \mathrm{~V}$ operation," in Proc. Symp. VLSI Circuits, 1998, pp. 228-229.

[19] A.-J. Annema, "Low-power bandgap references feature DTMOST's," IEEE J. Solid-State Circuits, vol. 34, pp. 949-955, July 1999.

[20] P. Malcovati et al., "Curvature compensated BiCMOS bandgap with 1 V supply voltage," in Proc. Eur. Solid-State Circuit Conf., 2000.

[21] M. Ugajin, "A 0.6-V voltage reference circuit based on $\Sigma-V t h$ architecture in CMOS/SIMOX," in Proc. Symp. VLSI Circuits, 2001, pp. 141-142.

[22] J. Y. Seto, "The electrical properties of polycrystalline silicon films," $J$. Appl. Phys., vol. 46, p. 5247, Dec. 1975. 


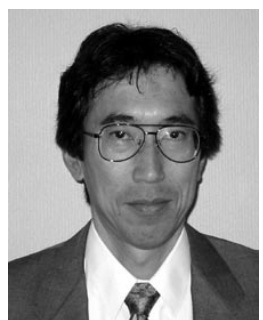

Hirobumi Watanabe (M'01) received the B.S. and M.P. degrees from Kyushu University, Fukuoka, Japan, in 1979 and 1981, respectively.

In 1981, he joined Ricoh Company Ltd., Japan. He was engaged in the research and development of a-Si sensor process and TFT devices with the R\&D Center, Ricoh, Yokohama. Since 1992, he has been working in the field of CMOS devises and recently he has worked on analog circuit design with the Electronic Devices Division, Ricoh Company Ltd., Osaka. His interests include robust circuit design with statistical extracted parameters

Dr. Watanabe is a member of the Institute of Electronics, Information and Communication Engineers of Japan and the Japan Society of Applied Physics.

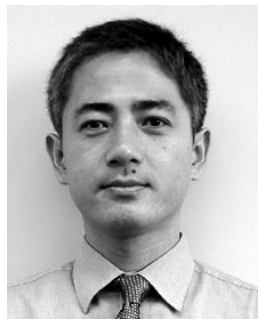

Shunsuke Ando received the B.S. degree from Tohoku University, Sendai, Japan, in 1986.

He then joined Ricoh Company Ltd., Tokyo, Japan. Since 1992, he has been engaged in the analog CMOS process and device. He is currently with Torex Device Company, Ltd., Tokyo.

Mr. Ando is a member of the IEEE Solid-State Circuits Society.

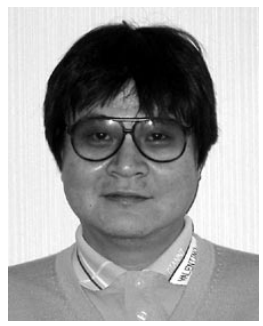

Hideyuki Aota received the B.E. degree in mechanical engineering from the Osaka Prefecture University, Osaka, Japan, in 1986.

He then joined Ricoh Company Ltd., Tokyo, Japan. He has been engaged in the field of CMOS devices, memory circuit design, and analog circuit design with the Electronic Devices Division of Ricoh Company Ltd., Osaka.

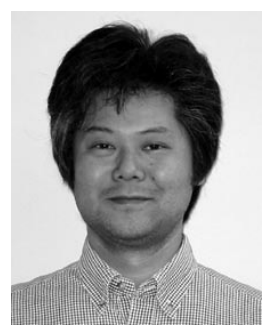

Masanori Dainin received the B.E. degree from Osaka Institute of Technology, Osaka, Japan, in 1988.

He then joined Ricoh Company Ltd., Osaka. He has been engaged in the research and development of power MOS process and devices with the Electronic Devices Division of Ricoh Company Ltd.

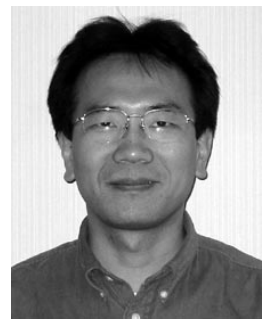

Yong-jin Chun received the B.E. and M.E. degrees in metallurgical engineering from the Hong-ik University, Korea, in 1988 and 1990, respectively, and the M.E. and Ph.D. degrees in materials science from the University of Tsukuba, Japan, in 1994 and 1997, respectively.

From 1997 to 2001, he was with NEC Fundamental Research Laboratories, where he was engaged in crystal growth and process development of nano scale compound semiconductors. In 2001, he joined Ricoh Company Ltd., Osaka, Japan. He has been engaged in the field of CMOS devices and analog circuit design with the Electronic Devices Division of Ricoh Company Ltd.

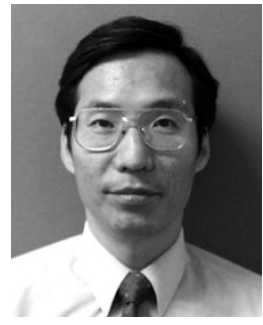

Kenji Taniguchi (SM'93-F'98) received the B.S., M.S., and Ph.D. degrees from Osaka University, Osaka, Japan, in 1971, 1973, and 1986, respectively.

From 1973 to 1986 , he was with the Toshiba Research and Development Center, Kawasaki, Japan, where he was engaged in process modeling and the design of MOS LSI fabrication technology. He was a Visiting Scientist with the Massachusetts Institute of Technology, Cambridge, from July 1982 to November 1983. Currently, he is a Professor of electronics engineering at Osaka University. His current research interests are in analog circuits, radio frequency circuits, device physics, and process technology.

Dr. Taniguchi is a member of the Japan Society of Applied Physics. 